\title{
Assessing the significance of sulfate driven cooling for the Deccan Traps
}

ISABEL M. FENDLEY ${ }^{1}$, NiCOLE MizRAHI ${ }^{1}$, TUSHAR MitTAL ${ }^{1}$, Courtney J. SPRAIN ${ }^{2}$, PAUl R. RENNE ${ }^{1,3}$, STEPHEN SELF ${ }^{1}$

${ }^{1}$ EPS Dept. UC Berkeley, Berkeley CA 94720

*correspondence isabel.fendley@berkeley.edu

${ }^{2}$ Dept. of Geological Sciences University of Florida, Gainesville, FL, 32611

${ }^{3}$ Berkeley Geochronology Center, Berkeley CA 94709

Large igneous province (LIP) eruptions impacted the environment through the emission of $\mathrm{CO}_{2}$ and $\mathrm{SO}_{2}$. The long lifetime of $\mathrm{CO}_{2}$ in the atmosphere can lead to volcanogenic warming persisting for $10 \mathrm{~s}$ or $100 \mathrm{~s}$ of thousands of years (ka). In contrast, $\mathrm{SO}_{2}$ release is hypothesized to cause significant and rapid global cooling for only the duration of each individual eruption, as the lifetime of sulfate aerosols is short $(<2$ years). The actual magnitude and duration of these cold "snaps" is not known, as due to their brevity, it is difficult to detect them in paleoclimate records with 1-2 ka resolution. In order to indirectly estimate their dynamics, we must address two key challenges: 1) did the sulfur (S) reach the stratosphere and was it widely distributed as required for global climate effects? and 2) how long and frequent were individual eruptions? At present, radioisotopic dating of Mesozoic LIPs is currently unable to resolve individual eruptions $(<10 \mathrm{ka})$.

We investigate the Deccan Traps (DT) LIP, using new highresolution $(2-7 \mathrm{ka})$ terrestrial mercury $(\mathrm{Hg})$ concentration and $\mathrm{S}$ and carbon $(\mathrm{C})$ isotope records spanning 66.3 to $65.1 \mathrm{Ma}$, from NE Montana. The $\mathrm{Hg}$ record has peaks and higher background during the main Deccan eruptive interval (66.3-65.6 Ma). Simultaneously, the $\mathrm{S}$ isotope composition shifts to values similar to mantle derived $\mathrm{SO}_{2}$. Both changes are independent of $\mathrm{S}$ and $\mathrm{C}$ concentration and lithology. This is the first direct evidence of global distribution of LIP-derived sulfate aerosols.

Using the $\mathrm{Hg}$ record coupled with an environmental $\mathrm{Hg}$ box model and statistical framework, we find that the eruptions on average lasted 50-500 years, occurred every 2-4 ka, and erupted $\sim 50 \mathrm{~km}^{3} / \mathrm{yr}$ of basalt. We use a modified LOSCAR model to predict the environmental effects of $\mathrm{CO}_{2}$ and $\mathrm{SO}_{2}$ for these eruptions and find a cooling of $\sim 2$ degrees during each eruption as well as long-term warming. We compare these quantitative predictions with global paleoenvironmental records and find systematic increases in variability in high-resolution records during this interval. Hence, in addition to $\mathrm{CO}_{2}$ warming, sulfurdriven cooling is confirmed to have been a significant process during the DT eruptive interval, resulting in environmental and ecological perturbations. 